\title{
UM ALEMÃO EM SANTA CATARINA: A COLEÇÃO ENTOMOLÓGICA FRITZ PLAUMANN
}

\begin{abstract}
RESUMO
O presente trabalho visa discorrer sobre a formação da coleção entomológica Fritz Plaumann. Tendo como entendimento que o ato de colecionar é uma prática cultural, buscamos compreender o caminho que a coleção levou até chegar ao Museu. Fritz Plaumnn apresenta-se como um colecionador-coletor, preocupado com as questões ambientais e com a produção de conhecimento, sua contribuição foi importante para o mapeamento da fauna entomológica do sul do Brasil. Nesse sentido, pretendemos discorrer sobre o colecionador, sua coleção e por fim, o museu.
\end{abstract}

\section{PALAVRAS-CHAVE:}

Fritz Plaumann; coleção entomológica; coleções científicas; Museu Entomológico Fritz Plaumann; ato de colecionar.

\author{
Aline Maisa Lubenow
}

\begin{abstract}
This work aims to discuss the formation of entomological collection Fritz Plaumann. With the understanding that the act of collecting is a cultural practice, we try to understand the way that the collection took to get to the Museum. Fritz Plaumann presents itself as a collector-collector concerned with environmental issues and with the production of knowledge as well. His contribution was important for mapping the insect fauna in southern Brazil. We intend to discuss on the collector, the collection and finally the museum.
\end{abstract}

\section{KEYWORDS}

Fritz Plaumann; Entomological collection; scientific collections; Museu Entomológico Fritz Plaumann; act of collecting.

IMestre em História das Ciências e da Saúde pela Casa de Oswaldo Cruz/Fundação Oswaldo Cruz. Atualmente é pesquisadora no Centro de Memória Alfa/MaxiCrédito-CEMAC. E-mail: alinemaisaa2I@gmail. com. 


\section{Introdução}

O presente trabalho objetiva discorrer sobre a formação da coleção entomológica Fritz Plaumann, a partir da década de 1930 até a chegada da coleção no Museu Entomológico Fritz Plaumann, permeando aspectos da vida do colecionador/coletor, destacando a atividade de coletor, além dos contatos científicos estabelecidos com a finalidade de identificar espécimes ou então comercializá-las. A coleção conta atualmente com aproximadamente 80 mil exemplares, 17 mil espécies dentre essas 1.500 descobertas pelo colecionador e descritas por pesquisadores tanto brasileiros como estrangeiros, foram mais de 60 anos coletando espécimes na região do Alto Uruguai Catarinense.

Fritz Plaumann é um imigrante alemão que chegou ao Brasil, juntamente com seus pais, em 1924 e se instalou na então colônia alemã de Nova Teutônia localizada na região oeste de Santa Catarina, hoje distrito de Nova Teutônia, Seara $-\mathrm{SC} .{ }^{2} \mathrm{~A}$ vinda da família para o Brasil foi motivada pela grave crise econômica em que se encontrava a Alemanha no período pós-primeira Guerra Mundial. Logo após sua chegada dá início a planejada coleção entomológica, no período conturbado de colonização e imigração do início do século XX. É inserido nesse contexto, ao qual o próprio Plaumann chamou de região remota, que deu início seu empreendimento como colecionador e coletor de insetos na "mata virgem" do chamado sertão catarinense. ${ }^{3}$

\section{O colecionador}

Ainda na Alemanha, Fritz Plaumann já havia iniciado uma pequena coleção entomológica, no qual teve que abandonar devido à mudança para o Brasil, iniciativa que foi estimulada pelo pai e seus professores da escola secundária. As narrativas que permeiam o período de sua vida na Alemanha estão cheias de referências que apontam a tradição de colecionar material de história natural na Alemanha no início do século XX. Sua família tinha o hábito de realizar passeios em florestas ou então em áreas ambientais. Plaumann pensava, desde a década de 1910, em seguir a "carreira de oficial florestal" (PLAUMANN in SPESSATO, 200I:2I). Esse interesse pela flora e fauna tinha como influência direta a escola, os professores e os pais. Plaumann descreve, em seu diário, que desde pequeno, ao ingressar na escola com seis anos, que seu interesse pela natureza era grande e evidencia que já tinha preferência pelo universo da fauna. $O$ trecho abaixo permite observamos seu encantamento pelo mundo dos insetos. ${ }^{4}$

Pelo Museu do Instituto recebi o primeiro impulso para fazer uma pequena coleção de insetos. $\mathrm{E}$, assim, certo dia, quando tínhamos aula ao ar livre no grande parque do Instituto, achei no tronco de uma árvore uma espécie de "sphingidae", antes nunca encontrada. Recebi licença do professor para leva-la para casa, onde pude incorporá-la á minha coleção (PLAUMANN, in SPESSATO, 2001:19).

Já no Brasil, os primeiros anos dos Plaumann são de adaptação e observação da nova terra, pois tudo era novo e estranho: o espaço, o clima, a vege-

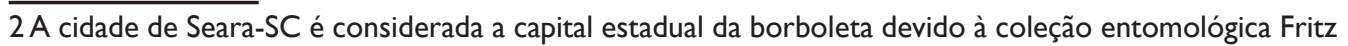
Plaumann.

$3 O$ início do século $X X$ é marcado pela intensa onda de imigração na região oeste de Santa Catarina, e também pelo processo de colonização da região. Tanto para o governo federal como estadual a região era considerada um grande vazio demográfico, desconsiderando a existência de caboclos e indígenas. Para mais informações ver em:RADIN, Carlos José. Representações da colonização. Chapecó:Argos, 2009. RENK, Arlene. O conhecimento do território:A Bandeira de Konder. In. A viagem de 1929: Oeste de Santa Catarina: documentos e leituras - Centro de Memória do Oeste de Santa Catarina. Chapecó:Argos, 2005. 4 As narrativas aqui apresentadas estão no diário de Fritz Plaumann, escrito pelo colecionar desde o ano de 1919até a década de 1990, relatos de sua vida na Alemanha e posteriormente no Brasil. 
tação, a nova língua, bem como a região longínqua de grandes centros urbanos, a escassez de recursos como alimentos, remédios, o atendimento médico e os mantimentos para a produção agrícola. É nessa região estranha e tão diferente, com flora e fauna exuberante e totalmente distante da sua Deutschland que Fritz Plaumann irá desenvolver o interesse cultivado ainda quando criança que era o de colecionar espécimes de história natural.

Durante a década de 1920 até meados da década de 1930, Plaumann trabalhava na agricultura, foi professor da colônia alemã de Nova Teutônia e ainda trabalhou como fotografo. Mesmo assim, associava às suas diferentes atividades ao interesse pela história natural. Mantinha registrado em seu diário, desde a sua chegada ao Brasil, os registros dos animais que encontrava e preparava para sua coleção particular, fazia o mesmo sobre aqueles que caçava para a subsistência da família, informando o peso, o tamanho, o nome vulgar e o científico, como registra "Há alguns dias eu havia atirado em um veado pardo (Mazama americana), com altura de $60 \mathrm{~cm}$, comprimento de $100 \mathrm{~cm}$, e peso de $40 \mathrm{~kg}$. Somente o couro valia 12,00. No outro dia matei um biguá (carbovigua), que se alimentava de peixes"(PLAUMANN in SPESSATO, 200I: 74).Além disso, realizava, ainda, um resumo da caça anual com a quantidade de animais abatidos. Os registros deixados por Plaumann, em seu diário, entre os anos de 1924 até meados da década de 1930, possibilitam a realização de um mapeamento da diversidade faunística encontrada nesse período no oeste de Santa Catarina.

$\mathrm{O}$ ano de 1925 foi muito importante para Plaumann, pois foi considerado pelo naturalista como o "lançamento da pedra fundamental" para suas pesquisas científicas, no Brasil, através das suas anotações meteorológicas: "Anotava três vezes por dia as indicações do barômetro, a temperatura, tipos e percentagem das nuvens, direção, e força do vento, trovoadas e precipitações, e outras observações de importância" (PLAUMANN in SPESSATO, 200I:53-56).

Pode-se se dizer que o início da vida de Fritz Plaumann, no novo país, foi uma mistura de estranhamento com fascínio. $O$ estranhamento com o clima, o lugar, as pessoas, com a língua e os costumes.A adaptação foi um longo processo, o qual perdurou durante anos. Mas, ao mesmo tempo, tinha o sentimento de fascínio pela diversidade de espécies, tanto pela fauna como flora, encontradas na região. Plaumannse constrói como um sujeito singular numa região que, para muitos, era isolada, um sinônimo de atraso, na qual a modernidade e a civilização ainda não haviam chegado. Região que, para o governo, deveria ser colonizada e explorada. Mesmo morando no denominado "sertão catarinense", chamado por ele de "região remota", o colecionador não se encontrava isolado, ao contrário, seus contatos científicos com inúmeros pesquisadores demostram sua conexão com diversos lugares do mundo, uma vez que Plaumann constituiu uma relevante e expressiva coleção de insetos, tornando-se conhecido no Brasil e no exterior. Os seus contatos com diferentes entomólogos e instituições nacionais e estrangeiras, podem ser considerados elementos fundamentais para compreendermos a constituição de sua coleção entomológica.

Fritz Plaumann era autodidata, após sua chegada ao Brasil seu estudo ocorreu somente através do autodidatismo. Entretanto, cabe pontuarmos a importância que os contatos científicos tiveram durante sua trajetória científica, pois em decorrência dessas relações que Plaumann adquiriu literatura específica para dar continuidade a seus estudos, além disso, adquiriu equipamentos para a coleta de espécimes. Pelo meio dos contatos científicos entre pesquisadores, coletores e colecionadores é que ocorreu a troca de material e a comercialização de espécimes. No caso de Plaumann algo essencial, pois o comércio de 
espécies foi sua principal fonte de renda desde meados da década de 1930. Podemos considerar que sua atividade de coleta, principalmente entomológica, não se restringiu somente à formação de uma coleção particular, mas também realiza trocas de espécimes e fornece exemplares para coletores particulares, pesquisadores e instituições científicas no Brasil e no exterior. A rede formada por instituições e atores, da qual Plaumann é o elemento-chave transcendem as fronteiras nacionais. ${ }^{5}$

Segundo Findlen (1996, apud LOPES, 200I), as coleções não começam nos museus, uma vez que os objetos considerados colecionáveis passam por uma longa viagem do campo até tornarem-se objetos de exposição nos museus. É o que observamos na coleção Fritz Plaumann. É no campo que a coleção começa a se formar, através da habilidade e das técnicas usadas pelo coletar, seja na captura dos insetos ou por meio dos conhecimentos sobre os locais de coleta. Segundo Lopes (200I), o ato de coletar implicava em conhecer o local a ser explorado, buscando compreender os contextos locais para seguir com as práticas científicas. Além disso, "coletar implicou viajar, seguir instruções, construir redes de coletores” (LOPES, 2001 I:885). Porém, não ficando restritas aos coletores, as conexões abrangeram outras redes como de colecionadores e comerciantes. Ao longo do século XIX, a América Latina torna-se o campo preferido dos colecionadores, principalmente da Europa Ocidental, muitas foram as amostras de animais e vegetais coletadas e enviadas para a Europa, sendo que seu destino era garantido nas exposições de museus. A coleta foi vista por naturalistas como uma ótima fonte de renda e a América do Sul um excelente lugar para suas coletas, pesquisas e encontrar novos espécimes (PODGORNY, 20I2).

No caso da coleção entomológica de Fritz Plaumann, todos os insetos foram coletados por ele mesmo.Além da montagem, etiquetagem e acondicionamento, tudo fora planejado por ele.A zona montanhosa do Alto Uruguai Catarinense foi o local de sua investigação, o espaço físico do fazer científico, o campo ${ }^{6}$.

[...] no campo científico da entomologia, saí da parcela de estudos e observações preliminares, passando para a investigação intensa, tanto nas pesquisas quanto na formação da coleção regional, planejada por mim, assim precisando fazer mudanças. Em primeiro lugar foi preciso arrumar madeira de cedro bem seca, caso contrário a coleção pegaria mofo e se estragaria. Planejei importar um tipo especial de turfa, para o fundo das gavetas. $O$ problema era encontrar alguém que fornecesse tal material em troca de material entomológico fornecido por mim.Visto que não havia capital necessário para essa obra que tinha em mente, até os alfinetes inoxidáveis eu tinha que importar. E para a aquisição da literatura necessária para poder levar avante os meus estudos, só me restava o mesmo caminho. Para essa finalidade pretendia entrar em contato com universidades da Alemanha, esperando ter êxito. Nessa esperança comecei a colecionar material entomológico para tal permuta. Já dispunha do conhecimento necessário para separar as espécies raras dos montes comuns. Já previa que esse labor exigiria uma assiduidade, se possível sem descanso, que seria dura (PLAUMANN in SPESSATO, 200 I:88).

\footnotetext{
5Para mais detalhes sobre para as relações científicas de Fritz Plaumann e a comercialização de espécimes ver em: LUBENOW, Aline Maisa. Enveredando pelas matas do sertão catarinense: a coleção entomológica Fritz Plaumann. (Dissertação de mestrado) Casa de Oswaldo Cruz/Fiocruz. Rio de Janeiro, 2015.

6 LOPES, M. M.Viajando pelo campo e pelas coleções: aspectos de uma controvérsia paleontológica. História, Ciências, Saúde. Manguinhos, vol.VIII (suplemento): 88I-97 200 I.
} 
$\mathrm{Na}$ imagem abaixo podemos visualizar um pouco do trabalho de coleta de insetos, observamos uma das principais áreas de coleta, a beira dos rios

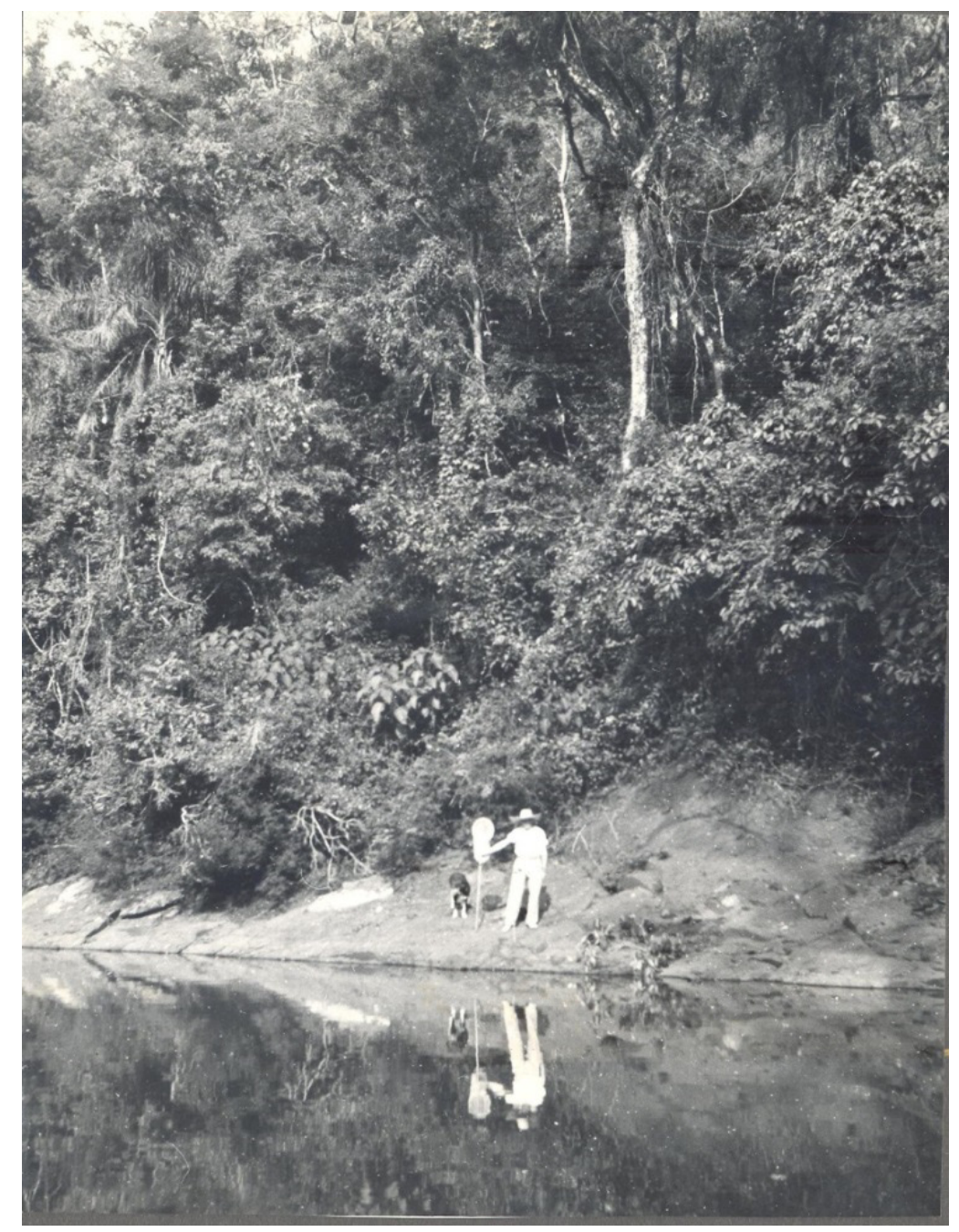

Foto 01: Fritz Plaumann coletando insetos, década de 1930, na Região do Alto Uruguai Catarinense.

Fonte: Casa de Fritz Plaumann.

No ano de 1933 o colecionador relata os resultados positivos de suas atividades de coleta, com a homenagem recebida pela coleta de nova espécie ao afirmar "Já recebia de especialistas as primeiras identificações. $O$ especialista da família Gyrinidae, senhor Ochs, escrevia-me contando que encontrara uma espécie nova, em homenagem ao coletor: Gyretesplaumanni" (PLAUMANN, IN SPESSATTO, 2001:95). Episódios como este se tornaram comuns nos mais de 60 anos como coletor, pois, muitas espécies descobertas por Plaumann foram descritas e publicadas por entomólogos ou zoólogos que, por sua vez, homenagearam o coletor ao nomear o novo inseto.

Ainda no começo da década de 1930, sua coleção contava com números expressivos e Plaumann começava a pensar em criar insetos:

A minha coleção contém agora 800 espécies de borboletas, entre essas raridades algumas como "Preponaprocheon, Preponaeugenes, Opsiphanesasorsa, Papiliolysithous”, ssp nova, etc. dava para criar algumas espécies raras de "Lepidópteros noturnos. [...] No meu grande porão (IOX|4), instalava repartições para a criação de Lepidopteras, besouros, Hymenoptera, percevejos, dípteros e outros insetos interessantes (PLAUMANN in SPESSATTO, 200I:95- I0I). 
No ano de 1949 Plaumann constrói uma casa $5 \mathrm{~m} \times$ 6, com o objetivo de ampliar a criação de besouros e borboletas, se pressupõem que esse empreendimento visasse à comercialização ou então estudos sobre os insetos.A prática cultural de coletar foi a principal fonte de renda de Fritz Plaumann durante toda sua vida a partir da intensa comercialização de espécimes e outros materiais biológicos, sustentando, dessa maneira, a planejada coleção entomológica. Plaumann também fotografava sua coleção, na imagem a seguir visualizamos parte da coleção de coleópteros.

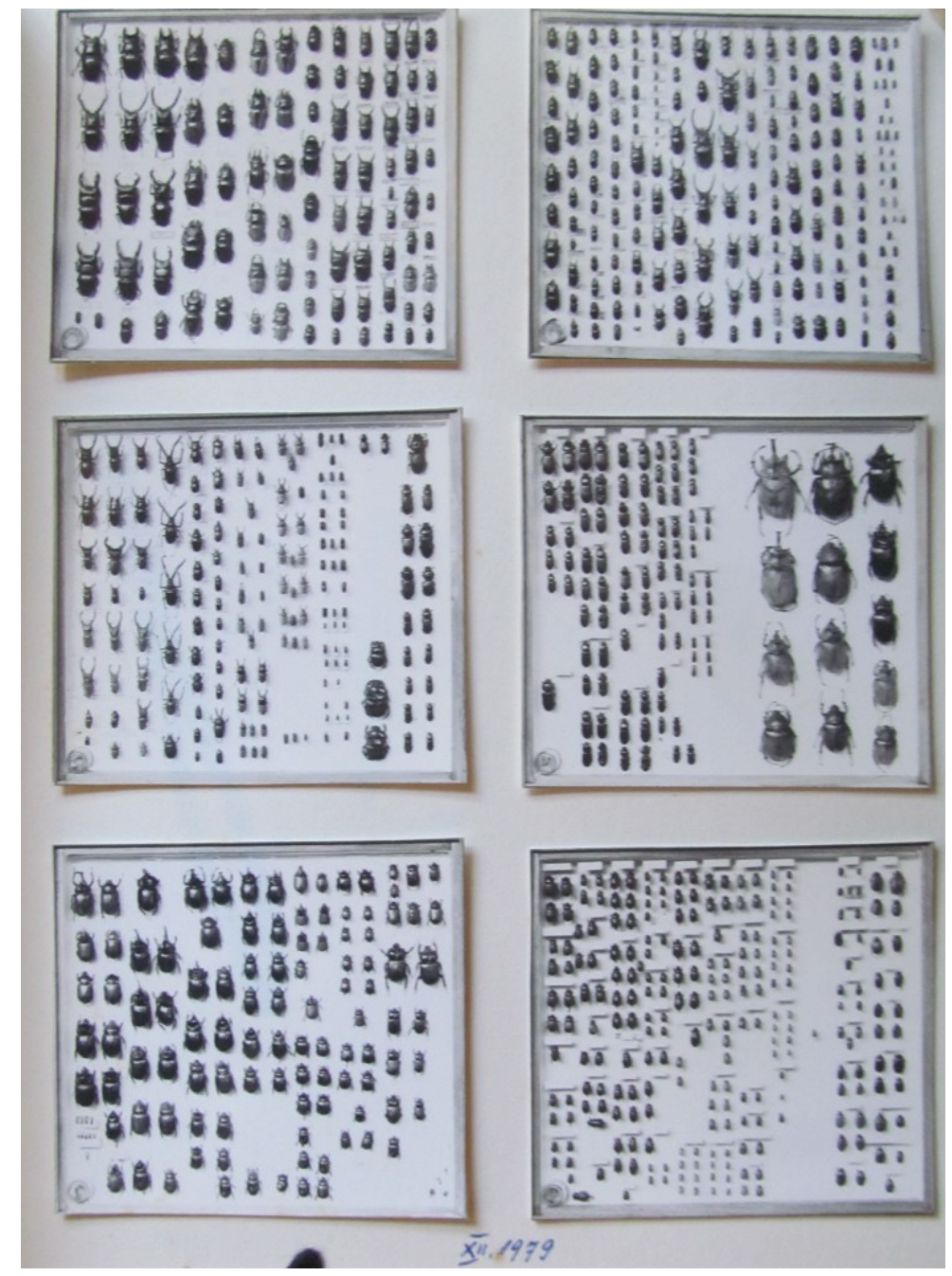

Foto 02: Exemplares da coleção de coleópteros fotografados por Fritz Plaumann em dezembro de 1979.

Fonte: Casa de Fritz Plaumann.

\section{O Museu Entomológico Fritz Plaumann}

No ano de 1967 entra em vigência no Brasil a lei $N^{\circ} 5.197$ de 03 de janeiro de 1967, conhecida como Lei de proteção à fauna, a qual restringiu o ato de coletar espécimes. Desde então, as atividades de coleta e comercialização foram duramente afetadas, pois perante a legislação ambiental brasileira Plaumann era considerado um amador, e somente podia coletar espécimes os chamados profissionais, quem estivesse vinculado a instituições científicas. A partir desse período Plaumann permaneceu em pleno contato com o IBDF (Instituto Brasileiro de Desenvolvimento Florestal) com a finalidade de obter licença para suas coletas e a comercialização de espécimes. Entretanto, em decorrência dos 
problemas em conseguir autorização para coletar insetos e encaminhar remessas para o exterior, e também devido à idade avançada, Fritz Plaumann decide vender sua coleção para a Prefeitura Municipal de Seara, culminando em seguida na construção do Museu Entomológico Fritz Plaumann.

A situação financeira para minha velhice exigia uma rápida melhora, visto que a aposentadoria que recebo do INPS nem alcança um salário mínimo. A única possibilidade seria a venda da minha Coleção Entomológica, na qual a Prefeitura de Seara estava interessada. Depois de acertados os pormenores, o Contrato de Compra e venda foi assinado pelo prefeito Aurélio Nardi, vice-prefeito Flávio Ragagnin e por mim, em 26.1 I.1982. Em dito contrato consta a cláusula: considerando o imenso valor científico da Coleção, a compradora assume o compromisso de que a mesma permanecerá como um todo sobre a denominação de "COLEÇÃO FRITZ PLAUMANN", devendo ser utilizada apenas para fins científicos, educativos, intelectuais e como comprovante de uma fauna regional em extinção. Contendo 60.000 exemplares, montados, rotulados e identificados. (PLAUMANN in SPESSATO, 2001: 233).

Com a grande divulgação por parte da prefeitura sobre a compra da coleção, inúmeros foram os visitantes que foram visitar a casa de Plaumann para conhecer a coleção entomológica. Em outras palavras, a coleção torna-se o museu.

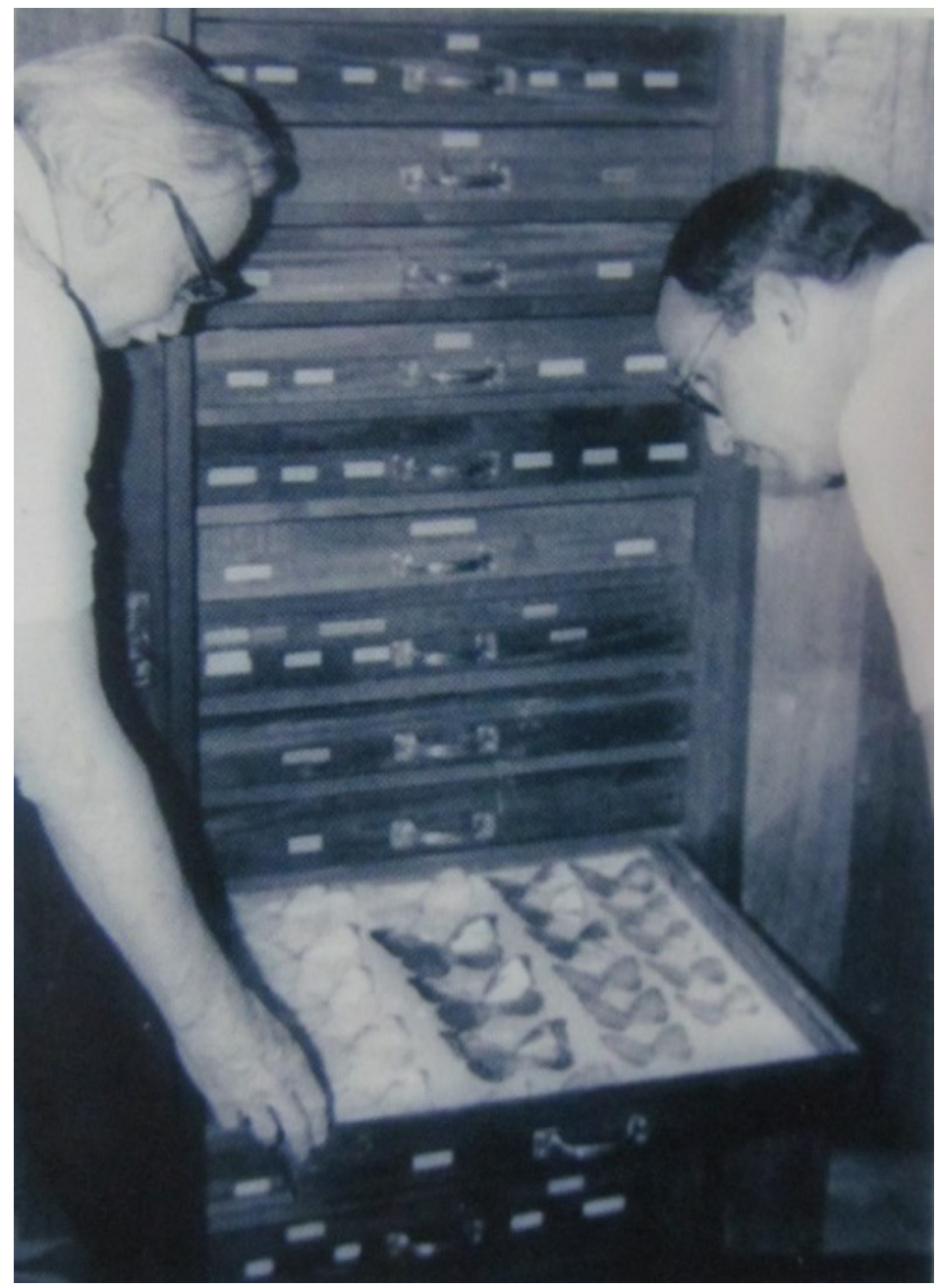

Foto 03: Fritz Plaumann mostra sua coleção em sua casa. Ele guardava a coleção em armários de 3 portas, sendo que cada repartição possui 16 gavetas com tampas de vidro, tamanho 52 x 48cm. Fonte: Casa de Fritz Plaumann. 
Mesmo após a venda da coleção, Plaumann não se afastou de sua "obra”, ao contrário, continuou trabalhando para a ampliação da coleção através das licenças expedidas pelo IBDF.Além disso, foi contratado pela prefeitura de Seara para ser o responsável pelo museu. $O$ colecionador e a coleção não se separaram.

No momento, o Museu Entomológico Fritz Plaumann conta com duas salas que abrigam a coleção entomológica, denominadas de "Obra". Dentro das caixas há um pequeno pote de vidro contendo naftalina, elemento auxiliar na conservação dos insetos. No museu também encontramos duas salas nas quais estão expostos diversos objetos utilizados para a coleta, manejo e pesquisas dos insetos, como por exemplo, as redes entomológicas, as pinças, o microscópio, um par de luvas, as lanternas, a máquina fotográfica, as amostras de desenhos feitas por Plaumann e algumas cópias de cartas de pesquisadores.Para Anna Larsen, a entomologia foi a área da história natural que desenvolveu o maior arsenal de equipamentos de campo, pois são muitos os materiais usados na coleta de insetos, processo complexo que exige cuidados, inclusive na maneira de matar, uma vez que uma técnica que funciona bem para besouros pode acabar com a asa de uma borboleta e, assim, afetar a classificação.

$\mathrm{Na}$ imagem abaixo podemos visualizar uma das salas que abrigam a coleção entomológica.

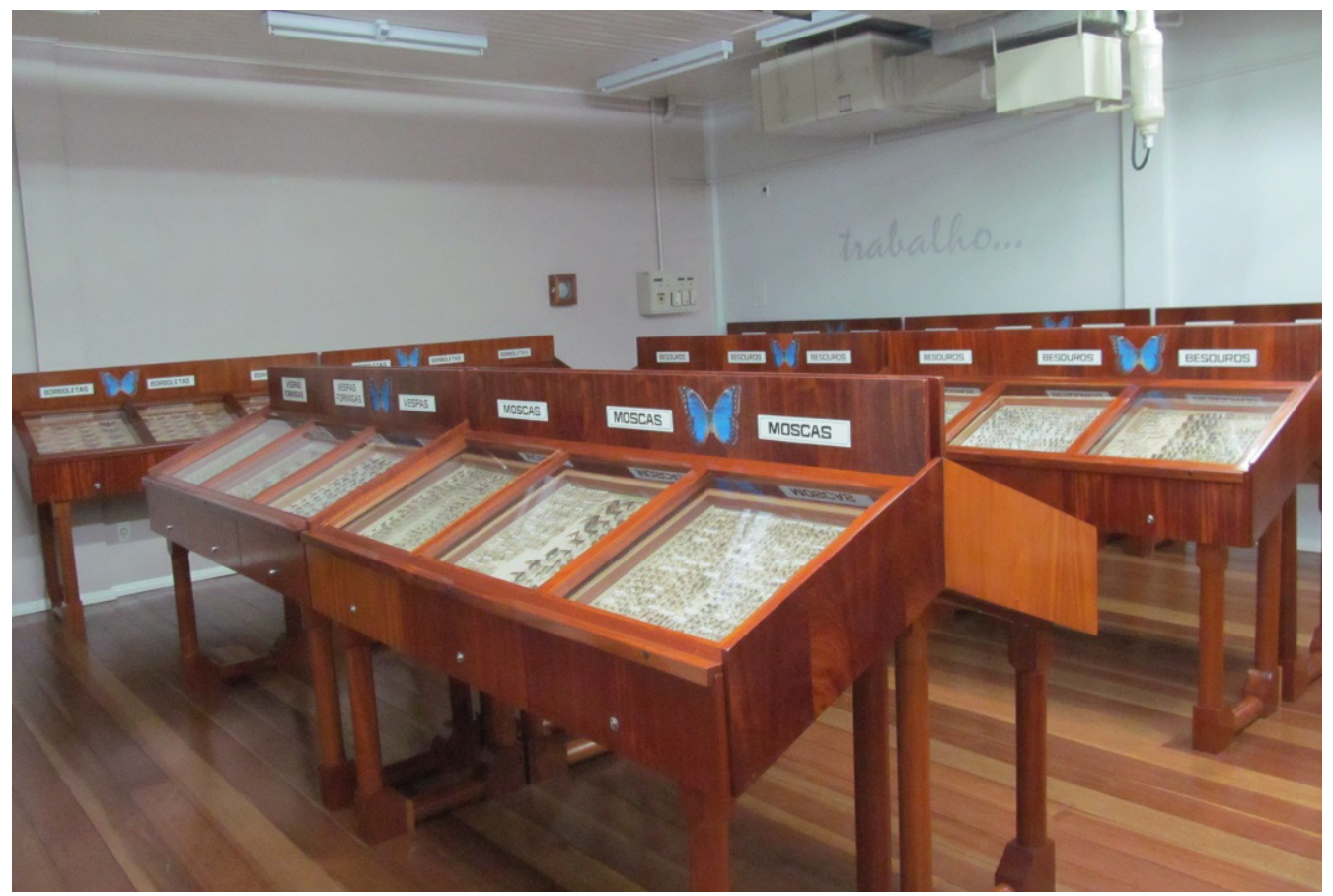

Foto 04: Sala que abriga a coleção entomológica no Museu Entomológico Fritz Plaumann. Fonte:Arquivo pessoal da autora.

A coleçãoconta com aproximadamente 73.036 mil exemplares, sendo que 9.601 são de espécies inseridas em 19 ordens de insetos 318 famílias e 2.219 gêneros. A partir destes números podemos afirmar que Plaumann catalogou e coletou aproximadamente $80 \%$ da fauna entomológica encontrada na Floresta Estacional semi-decidual e Floresta Ombrófila Mista do oeste de Santa Catarina.Além da beleza que rodeia o museu com seu espaço arborizado, é possível visitar o túmulo de Fritz Plaumann, localizado ao lado do Museu Entomológico Fritz Plaumann. ${ }^{7}$ Outro fator importante, é que o museu foi construiu na comunidade de Nova Teutônia,

\footnotetext{
${ }_{7}^{7}$ SILVA, da Rogério Rosa. A coleção entomológica do museu Fritz Plaumann. In. Biotemas, I I (2): I 57-I64, 1998.
} 
erguido na frente da residência de Fritz Plaumann, a coleção permaneceu na localidade onde foi formada.

Há no museu uma terceira sala chamada de sala da "curiosidade", na qual estão abrigados alguns achados de Plaumann durante suas idas ao campo coletar insetos, como, por exemplo, ossos de animais, pele de cobra, aranhas e, também, doações de outras regiões do Brasil, como um ovo de Ema e conchas.

Abaixo imagem da coleção de lepidópteros.

No caso da coleção entomológica de Plaumann, foram erguidas paredes

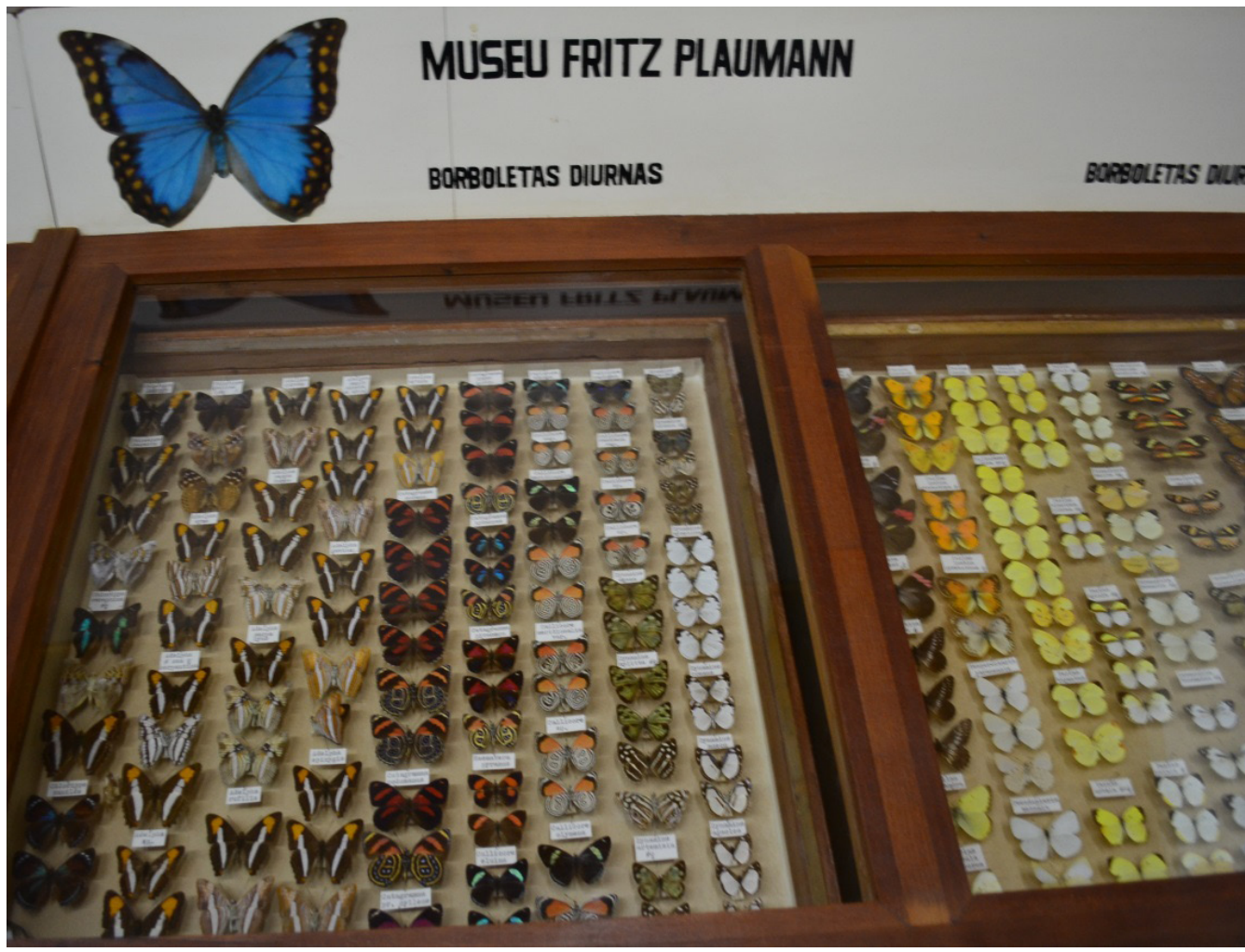

Foto 05: Coleção de lepidópteros do Museu Entomológico Fritz Plaumann. Fonte:Acervo pessoal da autora.

para ali repousá-la. Nesse espaço, a coleção está rodeada de cuidados, submetida a uma proteção especial, exposta de uma maneira que somente seja possível observá-la. Isso, para Pomian, significa que "Ao colocar objetos nos museus expõem-se ao olhar não só do presente, mas também das gerações futuras, como dantes se expunham outros ao dos deuses" (POMIAN, 1984: 84). A formação dos Museus de História Natural encontrava-se muito ligada ao colecionismo e era vista como a instituição de pesquisa e da divulgação da ciência, com coleções específicas, com o intuito de ordenar e classificar os objetos naturais (POSSAS, 2005).

No Brasil do século XIX é evidente a amplitude que tomou as atividades científicas oriundas da emergência da História Natural e da institucionalização das Ciências Naturais no país. Sobre o assunto, Lopes (1997: 323) enfatiza que os Museus atuavam como instituições que abrigavam "coleções de ciências naturais, arqueológicas e etnográficas".

Os Museus eram espaços em que os naturalistas se profissionalizavam e onde ocorria a especialização de diversos campos do conhecimento. O século XVIII é o palco das mudanças no sentido da especialização das coleções. "Os museus específicos tendem a reproduzir em seus arranjos uma ordem que 
acompanha as novas concepções científicas e as novas exigências metodológicas das Ciências da Natureza" (KURY; CAMENIETZKI, 1997, p. 57).

Além disso, as exposições das coleções abrigadas nos Museus serviam para divulgar e levar para a população o conhecimento sobre o mundo natural. Este é o cenário do Museu Real, posteriormente denominado Imperial e Nacional, nas primeiras décadas do século XIX, e que acabou por se disseminar através do país, com a criação do Museu Paranaense Emilio Goeldi em 1866, Museu Botânico do Amazonas em 1883, Museu Paulista em 1894, o Museu Rocha, por iniciativa particular, criado no Ceará em I887. No século $X X$, com a criação das universidades, cada vez mais foram surgindo iniciativas de criação de museus de história natural.

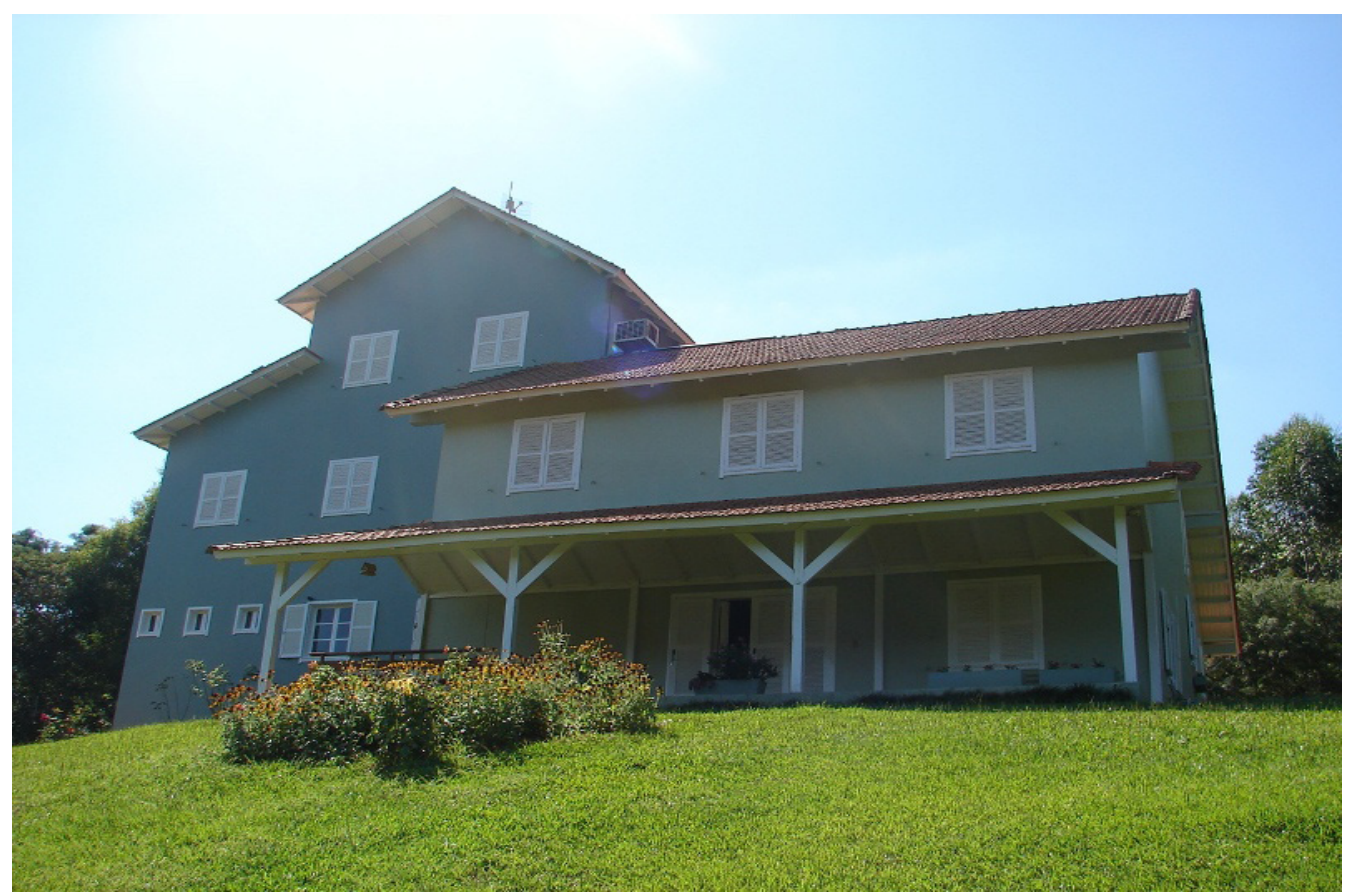

Foto 06: Museu Entomológico Fritz Plaumann. Fonte:Arquivo pessoal da autora.

A prática de colecionismos esteve presente na vida de Fritz Plaumann durante quase toda sua vida, desde a pequena coleção de insetos, ainda quando morava na Alemanha e, posteriormente, dando seguimento a essa prática cultural no Alto Uruguai Catarinense.Além disso, mesmo após a venda da coleção, devido ao trabalho que continuou a desenvolver no museu, ficou responsável pelos cuidados com a coleção, que continuou crescendo, principalmente com as coletas que continuou a realizar até o início da década de 1990, milhares foram às amostras que saíram da região do Alto Uruguai Catarinense para serem abrigadas em museus, universidades e coleções particulares, tanto brasileiras como para a Europa Ocidental, Estados Unidos e América Latina.

O Museu Entomológico Fritz Plaumann é um dos museus mais visitados da região oeste de Santa Catarina, com um público anual de aproximadamente 5 mil visitantes, ${ }^{8}$ em sua maioria são estudantes do ensino fundamental, médio e superior. Deste modo, consideramos a respectiva coleção uma ferramenta para o ensino de Ciências Naturais e diversas áreas, pois é fonte direta de informações sobre a biodiversidade. Além disso, as coleções entomológicas são

${ }^{8}$ No ano de 2014 o museu recebeu 4.7 I I visitantes e no ano de 20154.530 , dados coletados com a direção do museu. 
consideradas excelentes fontes de conhecimento taxonômico, sendo de grande utilização para a comunidade científica e para acadêmicos de várias áreas do conhecimento. Nesse sentido, as coleções são excelentes bancos de dados para a entomológica médica, que objetiva o estudo dos insetos transmissores de doenças aos homens e também para a entomológica agrícola, que direciona suas pesquisas aos insetos causadores de doenças nas lavouras.

Plaumann julgava sua atividade científica sempre em prol do conhecimento da fauna entomológica do Brasil. "Tão logo que o tempo permita, vou recomeçar com os meus trabalhos em prol da fauna brasileira e aumentar a coleção zoogeográfica regional a qual, afinal, vai trazer vantagens para outros cientistas de hoje e no futuro" (PLAUMANN in SPESSATO, 200I:206). Em suas narrativas fica evidente a preocupação com a classificação dos insetos, a identificação e a conservação. Para isso sempre utilizava de materiais e produtos adequados, com a finalidade dos insetos não se deteriorarem, preocupação essencial que fez com que a coleção entomológica perdurasse até os dias atuais em ótimo estado de conservação, permitindo a visitação de inúmeras pessoas, principalmente de estudantes, público alvo do Museu Entomológico Fritz Plaumann.

\section{Referências bibliográficas}

KURY, Lorelai; CAMENIETZKI, Carlos Ziller. Ordem e Natureza: coleções e cultura científica na Europa Moderna. Anais do Museu Histórico Nacional, vol. 29, 1997.

LARSEN, Anne. Equipment for the field. In. JARDINE, N.; SECORD, J.A. e SPARY, E.C. (eds). Cultures of natural history. Cambridge: Cambridge University Press, 1997 (1996).

LOPES, Maria Margaret. O Brasil descobre a pesquisa científica: os museus e as ciências naturais no século XIX. São Paulo: Hucitec, 1997.

LOPES, M. M.Viajando pelo campo e pelas coleções: aspectos de uma controvérsia paleontológica. História, Ciências, Saúde. Manguinhos, vol.VIII (suplemento): 88I-97 200I.

LUBENOW, Aline Maisa. Enveredando pelas matas do sertão catarinense: a coleção entomológica Fritz Plaumann. (Dissertação de mestrado) Casa de Oswaldo Cruz/Fiocruz. Rio de Janeiro, 2015.

PODGORNY, Irina. De cómoMylodonrobustussurgió de loshuesos de Glyptodon El comercio de huesosconelRío de la Plata y la sistemática de los mamíferos fósilesen I840. In.Rev. Museo La Plata, 20 I 2, SecciónPaleontología I2 (67):43-64. POMIAN, K. Enciclopédia Einaudi.V. I. Porto: Imprensa Nacional/Casa da Moeda, 1984

POSSAS Helga Cristina Gonçalves. Classificar e ordenar: os gabinetes de curiosidades e a história natural. FIGUEIREDO, Betânia Gonçalves; VIDAL, Diana Gonçalves (Org) Museus: dos Gabinetes de Curiosidade à Museologia Moderna. Belo Horizonte: Editora Argvmentvm, 2005.

SPESSATTO, Mary, Bortolanza. (org). O diário de Fritz Plaumann. Chapecó: Argos, $200 \mathrm{I}$. 